\title{
Parametric Analyses of the Dynamic Response and Fatigue Life of a Compliant Vertical Access Riser with Internal Flow
}

Fuheng Li

Department of Marine Engineering, College of Engineering, Ocean University of China, Qingdao, Shandong Province, China, Ifh7416@stu.ouc.edu.cn

Haiyan Guo

Department of Civil Engineering, College of Engineering, Ocean University of China, Qingdao, Shandong Province, China

Xiaomin Li

Department of Civil Engineering, College of Engineering, Ocean University of China, Qingdao, Shandong Province, China

Zhen Liu

Department of Marine Engineering, College of Engineering, Ocean University of China, Qingdao, Shandong Province, China

Honglu Gu

Department of Marine Engineering, College of Engineering, Ocean University of China, Qingdao, Shandong Province, China

See next page for additional authors

Follow this and additional works at: https://jmstt.ntou.edu.tw/journal

Part of the Fresh Water Studies Commons, Marine Biology Commons, Ocean Engineering Commons, Oceanography Commons, and the Other Oceanography and Atmospheric Sciences and Meteorology Commons

\section{Recommended Citation}

Li, Fuheng; Guo, Haiyan; Li, Xiaomin; Liu, Zhen; Gu, Honglu; and Cui, Peng (2021) "Parametric Analyses of the Dynamic Response and Fatigue Life of a Compliant Vertical Access Riser with Internal Flow," Journal of Marine Science and Technology. Vol. 29: Iss. 5, Article 5.

DOI: $10.51400 / 2709-6998.2466$

Available at: https://jmstt.ntou.edu.tw/journal/vol29/iss5/5

This Research Article is brought to you for free and open access by Journal of Marine Science and Technology. It has been accepted for inclusion in Journal of Marine Science and Technology by an authorized editor of Journal of Marine Science and Technology. 
Parametric Analyses of the Dynamic Response and Fatigue Life of a Compliant Vertical Access Riser with Internal Flow

\section{Authors}

Fuheng Li, Haiyan Guo, Xiaomin Li, Zhen Liu, Honglu Gu, and Peng Cui 


\title{
Parametric Analyses of the Dynamic Response and Fatigue Life of a Compliant Vertical Access Riser with Internal Flow
}

\author{
Fuheng $\mathrm{Li}^{\mathrm{a}}$, Haiyan Guo ${ }^{\mathrm{b}, *}$, Xiaomin $\mathrm{Li}^{\mathrm{b}}{ }^{\text {, Zhen Liu }}{ }^{\mathrm{a}}$, Honglu Gu ${ }^{\mathrm{a}}$, Peng Cui ${ }^{\mathrm{a}}$ \\ a Department of Marine Engineering, College of Engineering, Ocean University of China, Qingdao, Shandong Province, China \\ ${ }^{\mathrm{b}}$ Department of Civil Engineering, College of Engineering, Ocean University of China, Qingdao, Shandong Province, China
}

\begin{abstract}
Subsea interventions on wellheads can be directly performed from a platform using a compliant vertical access riser (CVAR), thereby incurring tremendous economic benefits. The dynamic response and the fatigue damage of a CVAR subjected to regular waves are important for assessing its application feasibility. Therefore, a reasonable numerical model is presented for assessing the damage to a CVAR considering the internal flow using the slender rod theory. The finite element method combined with a Newmark- $\beta$ scheme is employed to discretize the equations and update the time integration. The Palmgren-Miner rule is applied for fatigue life prediction, focusing on the wave-induced dynamic response and fatigue life of a CVAR with various parameters, including the wave height and period, internal flow, and external current. The results demonstrate that the dynamic response and the fatigue life of the CVAR are relatively sensitive to the wave height and the external current. The tension and the displacement decrease with the increasing excitation frequency, but the opposite is true for the fatigue life. In addition, the internal flow has a weak influence on the CVAR.
\end{abstract}

Keywords: Compliant vertical access riser, Slender rod theory, Dynamic response, Fatigue life

\section{Introduction}

$\mathrm{O}$ il and natural gas exploration activities have been extended to deeper waters due to increased fossil fuel consumption [25]. Under these circumstances, a steel catenary riser (SCR) may sustain excessive hang-off tension and suffer fatigue damage due to cyclic soil resistance [3,7]. The high cost and the large fluid force sound an alarm on the steel lazy wave riser (SLWR) due to its long buoyancy segments. A novel compliant vertical access riser (CVAR) can be regarded as a reliable and robust method for conveying synthetic gas and oil.

The concept of a CVAR, as shown in Fig. 1, was first proposed in a patent application [19]. This lower-tension compliant riser, characterized by its differentiated geometry, allows for production activities in deep water. The additional buoyancy module with a low factor isolates the riser motion from the top end. The buoyancy module with a high factor and the weight module ensure a longer fatigue life by keeping both ends nearly vertical. More crucially, they allow direct intervention to the wellhead from the platform. A CVAR provides substantial economic benefits for subsea production compared with an SCR and an SLWR.

A riser excited by regular waves can respond to large magnitudes of high-frequency oscillation and deformation. The resultant fatigue damage accumulation can compromise the system performance and integrity, ultimately leading to system failure if not addressed appropriately $[2,10]$. In addition, the internal flow density and the external current velocity inevitably influence the wave-induced dynamic responses and fatigue lives of risers [11]. Brinkmann and Whooley [4] utilized commercial 


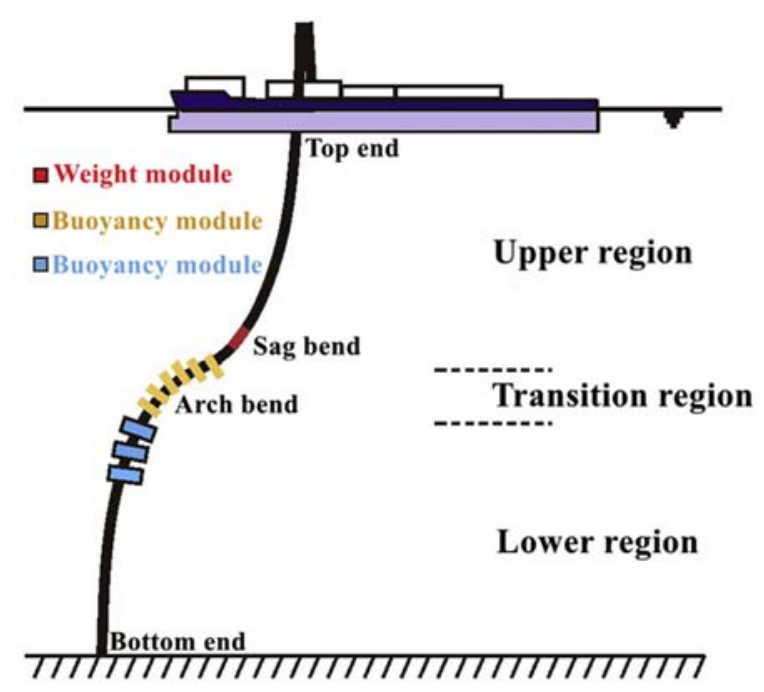

Fig. 1. Diagram of a CVAR (Lou et al., 2020).

software to analyze the dynamic response of a CVAR subjected to vessel motion. Mungall et al. [16] studied the extreme response and the fatigue damage of a CVAR based on Flexcom-3D. Because it is time-consuming to establish a numerical model and process the results using a cumbersome graphical user interface, commercial software programs, such as OrcaFlex, Flexcom-3D, and Riflex, are employed in the final stage of riser design for accurate results $[9,13]$. Engineers tend to use convenient simulation methods for the intermediate stages of riser design to adjust the riser parameters quickly. Martins et al. $[14,15]$ carried out studies on the optimal solution of the dynamic response of a CVAR subjected to vessel motion using the design of experiment (DOE) technology. Lou et al. [12,13] performed a simple numerical simulation of the dynamic response of a CVAR exposed to regular waves using virtual work and variational principles. However, there is still a limited understanding of the effect of the individual parameters, such as the wave height and period, inflow density, and external current velocity. Because the nonlinear dynamic analysis and fatigue life of a CVAR subjected to regular waves have not been exhaustively studied, an appropriate and robust mathematical model for capturing the nonlinear characteristics is of considerable interest.

The finite element method based on absolute node coordinates deserves further attention [22]. It not only ensures the accuracy of the calculation but also avoids the tedious coordinate transformation of the traditional finite element method. The slender rod theory used in this study, which can effectively solve the nonlinearity of large deformation for risers, is based on this method $[8,18]$. Evidence has shown that the static and dynamic behaviors of risers can be reasonably simulated using this method $[23,26]$.

The aim of this study is to identify the nonlinear wave-induced dynamic response and fatigue life of a CVAR due to its wave height and period, internal flow density, and current velocity based on the slender rod theory. The Morison equation is adopted to calculate the hydrostatic and hydrodynamic loads acting on the CVAR. The internal flow effect is quantified by adding a plug flow term to the effective tension equation. The finite element method is used to discretize the equations. The dynamic responses are evaluated using numerical time integration based on Newmark's method with direct iteration. After determining the total number of cycles in the time domain using the rainflow method, the Palmgren-Miner rule is used to estimate the fatigue life.

\section{Mathematical model}

\subsection{Slender rod theory}

In this study, the slender rod theory is applied to model the dynamic behavior of the CVAR. As shown in Fig. 2, the riser configuration is described by the rod centerline position $r(s, t)$, which is similar to the line element used in commercial software. The buoyancy module is approximated as a single riser with equivalent axial and flexural stiffness. Based on the conservation of linear momentum, the motion equation of the extensible rod with a linear and small stretch can be expressed as shown below [5]:

$$
\begin{aligned}
& -\left(E I r^{\prime \prime}\right)^{\prime \prime}+\left(\lambda r^{\prime}\right)^{\prime}+q=\rho_{r} \ddot{r} \\
& \frac{1}{2}\left(r^{\prime} \cdot r^{\prime}-1\right)^{\prime}=\frac{\lambda}{E A}
\end{aligned}
$$

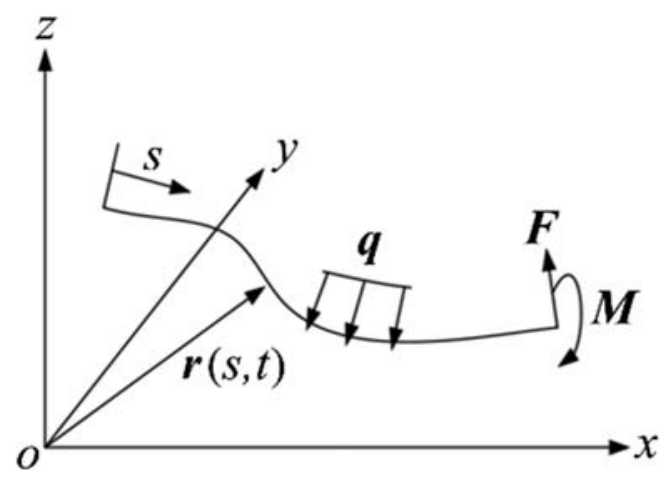

Fig. 2. Diagram of rod coordinates (Garrett, 1982). 
where $E I$ is the bending stiffness, $\lambda=T-E I \kappa^{2}, T$ is the wall tension of the rod, $\kappa$ is the curvature $(\kappa=$ $\left.\left|\boldsymbol{r}^{\prime \prime}\right|\right), \boldsymbol{r}^{\prime}$ denotes the tangent vector of the $\operatorname{rod}, \rho_{r}$ is the mass per unit length of the rod, $E A$ is the axial stiffness, and $q$ is the applied force per unit length of the rod, which is given as:

$q=w+B+\left(P_{r e s} r^{\prime}\right)^{\prime}+F^{d}$

where $w$ denotes the gravity per unit length of the riser, $B$ is the buoyancy force per unit length of the riser, $P_{r e s}$ is the pressure difference between the inside and outside of the riser, and $F^{d}$ is the hydrodynamic force induced by waves and currents. The regular wave is identified using the Airy wave theory and $F^{d}$ is obtained using the Morison equation:

$$
\begin{aligned}
F^{d}= & \rho_{w} \frac{\pi D^{2}}{4} \dot{U}^{n}+C_{a} \rho_{w} \frac{\pi D^{2}}{4}\left(\dot{U}^{n}-\dot{r}^{n}\right)+\frac{1}{2} C_{D} \rho_{w} D\left|U^{n}-\dot{r}^{n}\right| \\
& \left(U^{n}-\dot{r}^{n}\right)
\end{aligned}
$$

where $\rho_{w}$ is the seawater density, $D$ is the riser diameter, $C_{a}$ is the additional mass coefficient, $C_{D}$ is the drag force coefficient, $U^{n}$ and $\dot{U}^{n}$ are the fluid velocity and the acceleration normal to the riser, respectively, $\dot{r}^{n}$ and $\dot{r}^{n}$ are the normal velocity and the acceleration of the rod, respectively.

The mixture of oil, gas, and water at high temperatures and pressures contributes to the complex effect of the internal fluid. To simplify the model, the internal flow is identified and quantified with the plug flow term, and the force induced by the internal flow $f(s, t)$ on the riser is obtained as follows:

$f(s, t)=-m_{f} \frac{D^{2} r}{D t^{2}}=-m_{f}\left(\frac{\partial^{2} r}{\partial t^{2}}+2 v \frac{\partial^{2} r}{\partial s \partial t}+v^{2} \frac{\partial^{2} r}{\partial s^{2}}\right)$

where the first term is the inertial force, the second term is the Coriolis force, and the third term represents the centrifugal forces.

Finally, the riser motion equation is obtained as:

$$
\left(\rho_{r}+m_{f}\right) \ddot{r}+C_{A} \ddot{r}_{n}+2 m_{f} U \dot{r}+\left(E I r^{\prime \prime}\right)^{\prime \prime}-\left(\bar{\lambda} r^{\prime}\right)^{\prime}=\bar{w}+F^{d}
$$

where $C_{A}=C_{a} \rho_{w} \frac{\pi D^{2}}{4}, \bar{\lambda}=T+P_{r e s}-E I \kappa^{2}=T_{e}-$ $E I \kappa^{2}, T_{e}=T+p_{o} A_{o}-p_{i} A_{i}, A_{0}$ and $A_{i}$ are the outer and inner diameters, respectively, and $\bar{w}=w+B$ is the effective gravity.

\subsection{Finite element discretization}

The governing equation and the deformation condition can be written in the tensor form as follows:

$-\left(\rho_{r}+m_{f}\right) \ddot{r}_{i}-C_{A} \dot{r}_{i}^{n}-2 m_{f} v \dot{r}_{i}^{\prime}-\left(E I r^{\prime \prime}\right)^{\prime \prime}+\left(\bar{\lambda} r^{\prime}\right)^{\prime}+\bar{w}_{i}+\bar{F}_{i}^{d}=0$

$\frac{1}{2}\left(r_{n}^{\prime} r_{n}^{\prime}-1\right)-\frac{\bar{\lambda}-p_{0} A_{0}+p_{i} A_{i}+m_{f} v^{2}}{E A}=0$

The variables $r_{i}(s, t)$ and $\bar{\lambda}(s, t)$ are expressed as:

$r(s, t)=\sum_{l=1}^{4} A_{l}(s) U_{l}(t)$

$\bar{\lambda}(s, t)=\sum_{k}^{3} P_{k}(s) \bar{\lambda}_{k}(t)$

where $A_{l}(s)$ and $P_{k}(s)$ represent the cubic and quadratic Hermite functions, respectively, $s$ is the range of the element length $L$, which varies from $0<s<L, U_{l}(t)$ is the position and tangent vector, and $\bar{\lambda}_{k}(t)$ represents the effective tension vectors.

The governing equations can be rewritten as follows:

$\left(M_{i j l k}+M_{i j l k}^{a}\right) \ddot{U}_{j k}+C_{i j l k}^{f} \dot{U}_{j k}+\left(K_{i j l k}^{1}+\bar{\lambda}_{n} K_{n i j l k}^{2}\right) U_{j k}-F_{i l}=0$

$G_{m}=A_{m i l} U_{k i} U_{k l}-B_{m}+C_{m n}\left(h_{n}-\bar{\lambda}_{n}\right)=0$

where $\quad M_{i j l k}=\quad \int_{0}^{L}\left(\rho+\quad m_{f}\right) A_{l} A_{k} \delta_{i j} d s K_{i j l k}^{1}=$ $\int_{0}^{L} E I A_{l}^{\prime \prime} A_{k}^{\prime \prime} \delta_{i j} d s, \quad K_{n i j l k}^{2}=\int_{0}^{L} P_{n} A_{l}^{\prime} A_{k}^{\prime} \delta_{i j} d s, \quad M_{i j l k}^{a}=$ $C_{A}\left[\int_{0}^{L} A_{l} A_{k} \delta_{i j} d s-\left(\int_{0}^{L} A_{l} A_{k} A_{s}^{\prime} A_{t}^{\prime} d s\right) U_{i t} U_{j s}\right], h_{n}=A_{o} P_{o n}-$ $A_{i} P_{i n}-m_{f n} v^{2}, \delta=\left\{\begin{array}{l}1, i=j \\ 0, i=j\end{array}, C_{m n}=\frac{1}{E A} \int_{0}^{L} P_{m} P_{n} d s\right.$, $C_{i j l k}^{f}=\int_{0}^{L} 2 m_{f} v A_{l}^{\prime} A_{k} \delta_{i j} d s$.

\subsection{Static and dynamic solutions}

The inertial force is excluded for the static simulation.

$$
\begin{aligned}
& R_{i l}=\left(K_{i j l k}^{1}+\lambda_{n} K_{n j i l k}^{2}\right) U_{j k}-F_{i l}=0 \\
& G_{m}=A_{m i l} U_{k i} U_{k l}-B_{m}+C_{m n}\left(h_{n}-\bar{\lambda}_{n}\right)=0
\end{aligned}
$$

The Newton-Raphson method is used to solve the above algebraic equations. This method assumes that the unknown values in the iterative step 
$\mathrm{n}$ are $U^{(n)}$ and $\lambda^{(n)}$. The value is expressed using the Taylor expansion:

$$
\begin{aligned}
& R_{i l}^{(n+1)}=R_{i l}^{(n)}+\frac{\partial R_{i l}}{\partial U_{j k}}\left(\Delta U_{j k}\right)+\frac{\partial R_{i l}}{\partial \lambda_{n}}\left(\Delta \lambda_{n}\right)=0 \\
& G_{m}^{(n+1)}=G_{m}^{(n)}+\frac{\partial G_{m}}{\partial U_{j k}}\left(\Delta U_{j k}\right)+\frac{\partial G_{m}}{\partial \lambda_{n}}\left(\Delta \lambda_{n}\right)=0
\end{aligned}
$$

Equations (15) and (16) can be rewritten in matrix form as:

$$
\begin{aligned}
& {\left[\begin{array}{ll}
K_{i j l k}^{t 0(n)} & K_{i \ln }^{t 1(n)} \\
D_{m j k}^{t 0(n)}+D_{m n}^{t 0(n)} & D_{m n}^{t 1(n)}
\end{array}\right]\left\{\begin{array}{l}
\Delta U_{j k} \\
\Delta \lambda_{n}
\end{array}\right\}=\left\{\begin{array}{l}
-R_{i l}^{(n)} \\
-G_{m}^{(n)}
\end{array}\right\}} \\
& K_{i j l k}^{t 0(n)}=K_{i j l k}^{1}+\lambda_{n}^{(n)} K_{i j l k}^{2}, K_{i 1 n}^{t 1(n)}=K_{n i j l k}^{2} U_{j k}^{(n)}=\left(\int_{0}^{L} P_{n} A_{l}^{\prime} A_{k}^{\prime} \delta_{i j} d s\right), \\
& D_{m n}^{t 1(n)}=-\frac{1}{E A} \int_{0}^{L} P_{n} P_{m} d s, D_{m j k}^{t 0(n)}=\left(\int_{0}^{L} P_{n} A_{k}^{\prime} A_{p}^{\prime} d s\right) U_{j p}^{(n)}, \\
& D_{m n}^{t 0(n)}=\frac{\partial C_{m n} h_{n}}{\partial U_{j k}}=\frac{\partial}{\partial U_{j k}} C_{m n}\left(A_{o} P_{o n}-A_{i} P_{i n}-m_{f} v^{2}\right), \\
& R_{i j}^{(n)}=\left(K_{i j l k}^{1}+\lambda_{n} K_{i j l k}^{2}\right) U_{j k}^{(n)}-F_{i l}, h_{n}=A_{o} P_{o n}-A_{i} P_{i n}-m_{f} v^{2}, \\
& G_{m}^{(n)}=A_{m i l} U_{k i}^{(n)} U_{k l}^{(n)}-B_{m}+C_{m n}\left(h_{n}-\lambda_{n}^{(n)}\right) .
\end{aligned}
$$

The Newmark- $\beta$ method is a classical integral method commonly used in dynamic analysis, and the integral parameters $\gamma$ and $\beta$ are 0.5 and 0.25 , respectively. The tangent stiffness matrix equation can be written as [17]:

$$
\left[\begin{array}{ll}
\widehat{K}_{t 0} & \widehat{K}_{t 1} \\
\widehat{D}_{t 0} & \widehat{D}_{t 1}
\end{array}\right]\left\{\begin{array}{l}
\Delta U_{j k} \\
\Delta \lambda_{n}
\end{array}\right\}=-\left\{\begin{array}{l}
\widehat{R}_{i l} \\
G_{m}
\end{array}\right\}
$$

where $\widehat{K}_{t 0}=K_{i j l k}^{1}+\lambda_{n} K_{n i j l k}^{2}+\frac{1}{\beta \Delta t^{2}} \widehat{M}_{i j l k}, \widehat{D}_{t 1}=-C_{m n}=$ - $\quad \frac{1}{E A} \int_{0}^{L} P_{m} P_{n} d s, \quad \widehat{D}_{t 0}=\left(\int_{0}^{L} P_{n} A_{k}^{\prime} A_{p}^{\prime} d s\right) U_{j p}+$ $\frac{\partial}{\partial U_{j k}} C_{m n}\left(A_{o} P_{o n}-A_{i} P_{i n}-m_{f} v^{2}\right), \widehat{K}_{t 1}=K_{n i j k}^{2} U_{j k}, \widehat{R}_{i l}=$ $\widehat{M}_{i j l k} \ddot{U}_{j k}+\left(K_{i j l k}^{1}+\lambda_{n} K_{n j i l k}^{2}\right) U_{j k}-F_{i l}, \quad G_{m}^{(n)}=$ $A_{m i l} U_{k i}^{(n)} U_{k l}^{(n)}-B_{m}+C_{m n}\left(h_{n}-\lambda_{n}^{(n)}\right)$.

The following incremental-iterative manner of the predictor-corrector method is used to obtain the exact solution in each time step:

(1) Initial Conditions

$$
u^{(0)}=0, \quad \dot{u}^{(0)}=0, \quad \ddot{u}^{(0)}=0 .
$$

(2) Estimate

$$
\begin{aligned}
\ddot{u}^{(n)}= & \ddot{u}^{(n-1)}, \dot{u}^{(n)}=\dot{u}^{(n-1)}+\Delta t(1-\gamma) \ddot{u}^{(n-1)}+\Delta t \gamma \ddot{u}^{(n)} \\
u^{(n)}= & u^{(n-1)}+\Delta t \dot{u}^{(n-1)}+\Delta t^{2}(0.5-\beta) \ddot{u}^{(n-1)} \\
& +\Delta t^{2} \beta \ddot{u}^{(n)}, \lambda^{(n)}=\lambda^{(n-1)} .
\end{aligned}
$$

(3) Increment

$\delta^{(n)}=\left[K_{T}\right]^{-1}\{R\}$.

(4) Correction

$u^{(n+1)}=u^{(n)}+\delta u^{(n)}, \dot{u}^{(n+1)}=\dot{u}^{(n)}+\frac{\gamma}{\beta \Delta t} \delta u^{(n)}$,
$\ddot{u}^{(n+1)}=\ddot{u}^{(n)}+\frac{1}{\beta \Delta t^{2}} \delta u^{(n)}, \lambda^{(n+1)}=\lambda^{(n)}+\delta \lambda^{(n)}$.

(5) Steps (2)-(4) are repeated for all the time steps.

The calculation of the static and dynamic responses of the CVAR is performed using MATLAB.

\subsection{Fatigue theory}

The S-N approach is one of the commonly used methods for fatigue life prediction [21]:

$\log N=\log a-m \log \Delta \sigma$

where $N$ is the number of cycles to failure, $\Delta \sigma$ is the stress amplitude, $\log a$ is the intercept of the S-N curve with double log coordinates, and $m$ is the slope of the S-N curve with double log coordinates, as shown in Fig. 3. In this study, the related parameters are taken as: $\log a=11.687$ and $m=3$.

The fatigue damage is calculated with the Palmgren-Miner linear damage accumulation hypothesis (Miner's rule):

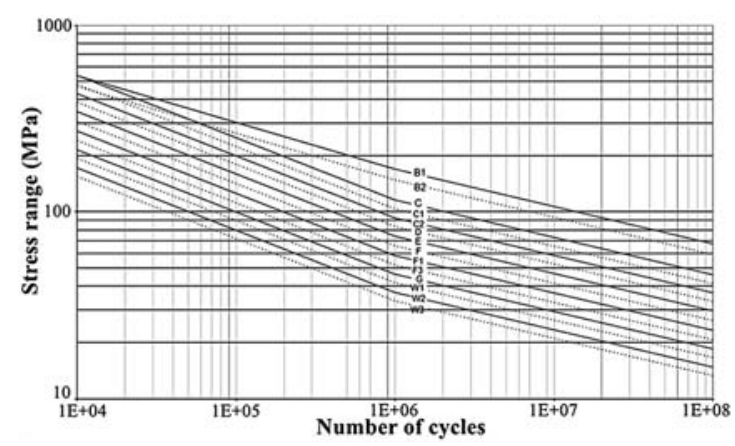

Fig. 3. Diagram of the S-N curve [20]. 
$D=\sum_{i} \frac{n\left(S_{i}\right)}{N\left(S_{i}\right)}$

where $D$ is the cumulative structural fatigue damage, the reciprocal of which gives the fatigue life; $n\left(S_{i}\right)$ is the cycle number of the stress amplitude, which is based on the rainflow counting method [1]; $N\left(S_{i}\right)$ is the maximum cycle number from the $S-N$ curve.

\section{Model validation}

To validate the applicability of the present model, we investigate the static and dynamic responses of the steep wave riser described by Liu and Guo (2018). The key parameters of the riser are listed in Table 1. A static comparison of the calculation cases in Fig. 4 shows good agreement between the proposed model and Orcaflex. Fig. 5 (a) and (b) show the time series of the $x$-direction displacements at $130 \mathrm{~m}$ and $942 \mathrm{~m}$ near the top end with the excitation of regular waves (i.e., height of $6 \mathrm{~m}$ and period of $12 \mathrm{~s})$. The obtained curves exhibit good consistency. Additionally, it should be pointed out that the dynamic amplitude is relatively small due to the long length the riser.

To further validate the present model, the response of a free-hanging riser for the combination of the x-direction current (i.e., at $0.2 \mathrm{~m} / \mathrm{s}$ and $0.3 \mathrm{~m} /$ s) and the regular wave (i.e. height of $10 \mathrm{~m}$, and period of $10 \mathrm{~s}$ ) is predicted and compared with the Orcaflex results. The parameters of the riser are listed in Table 2. The time series comparisons of the top tension are presented in Fig. 6. These comparisons confirm the feasibility and accuracy of the

Table 2. Properties of the free hanging riser.

\begin{tabular}{llll}
\hline Properties & Value & Properties & Value \\
\hline Total length $(\mathrm{m})$ & 170 & Bending stiffness $(\mathrm{N})$ & $1.208 \mathrm{e} 5$ \\
Internal diameter $(\mathrm{m})$ & 0.30 & Axial stiffness $\left(\mathrm{N} \cdot \mathrm{m}^{2}\right)$ & $5 \mathrm{e} 8$ \\
Outer diameter $(\mathrm{m})$ & 0.396 & Added mass coefficient & 1.0 \\
Dry mass $(\mathrm{kg} / \mathrm{m})$ & 165 & Drag coefficient & 1.0 \\
\hline
\end{tabular}

Table 1. Properties of the steep wave riser.

\begin{tabular}{llll}
\hline Properties & Value & Properties & Value \\
\hline Steel riser density $\left(\mathrm{kg} / \mathrm{m}^{3}\right)$ & 7860 & Lower section length $(\mathrm{m})$ & 600 \\
Outer diameter $(\mathrm{m})$ & 0.20 & Buoyancy section length $(\mathrm{m})$ & 300 \\
Inner diameter $(\mathrm{m})$ & 0.18 & Upper section length $(\mathrm{m})$ & 1300 \\
Elastic module $(\mathrm{GPa})$ & 206 & Seawater density $\left(\mathrm{kg} / \mathrm{m}^{3}\right)$ & 1024 \\
Internal flow density $(\mathrm{kg} / \mathrm{m})$ & 998 & Internal flow velocity $(\mathrm{m} / \mathrm{s})$ & 0 \\
\hline
\end{tabular}
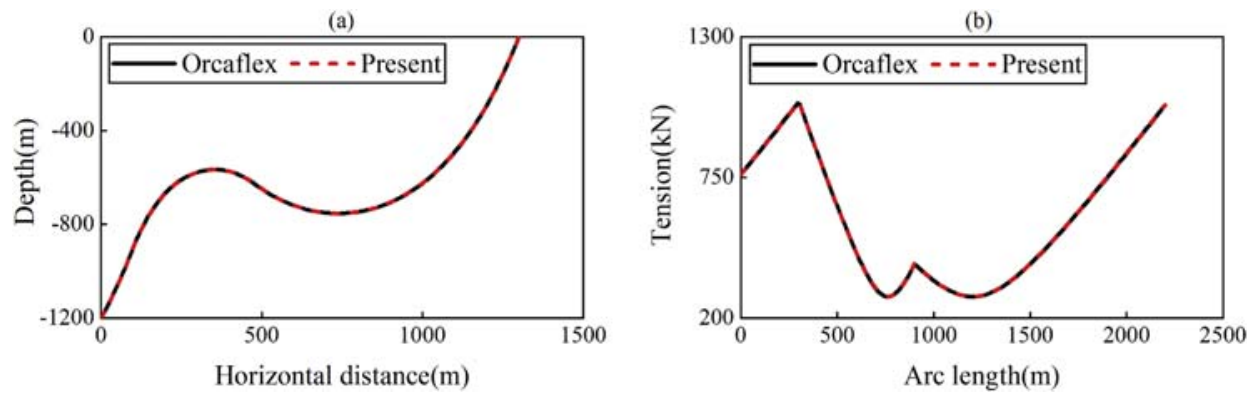

Fig. 4. Comparison of static response. (a) Configuration. (b) Effective tension.
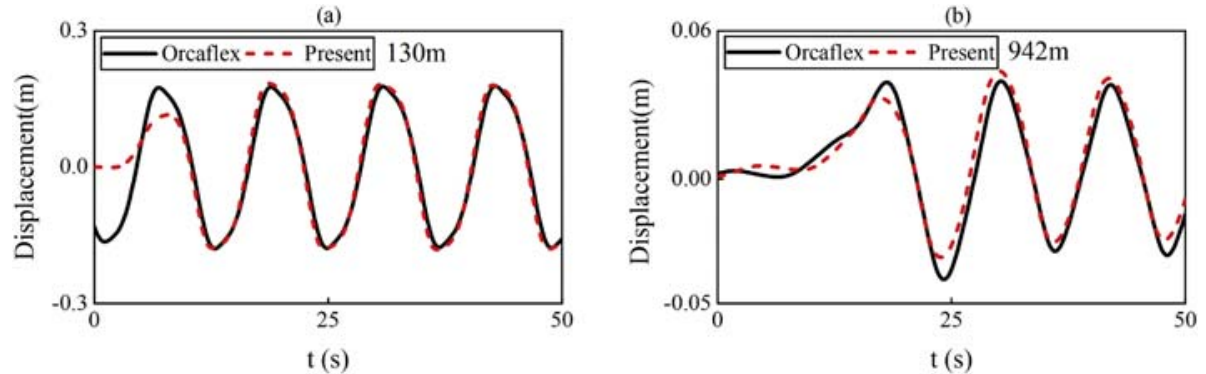

Fig. 5. Time series comparisons of $x$-direction displacement. (a) $130 \mathrm{~m}$. (b) $942 \mathrm{~m}$. 

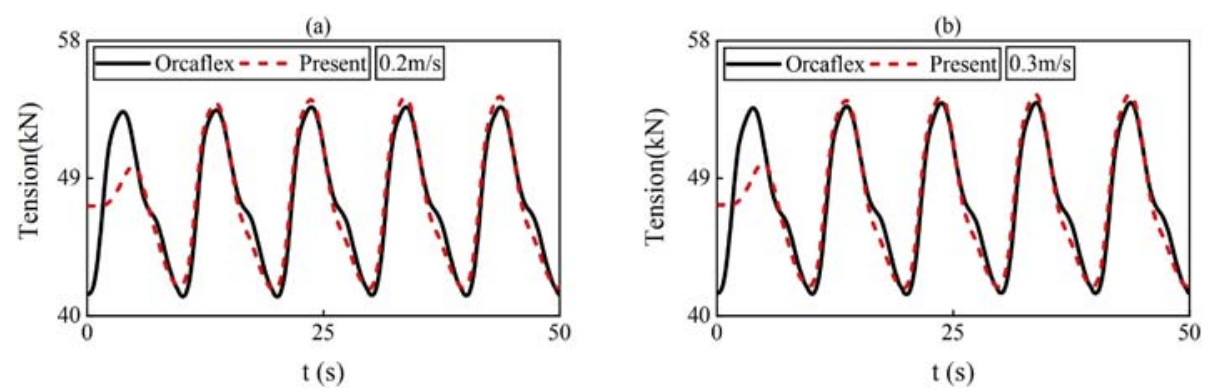

Fig. 6. Time series comparisons of top tension for the free-hanging riser subjected to regular waves combined with different currents. (a) $0.2 \mathrm{~m} / \mathrm{s}$. (b) $0.3 \mathrm{~m} / \mathrm{s}$.

slender rod theory in modeling the dynamic behavior of marine risers.

\section{Numerical results}

This section describes the examination of the influence of the wave height $(\mathrm{H})$, period $(\mathrm{T})$, external current velocity $(v)$, and internal flow density $(\rho)$ on the dynamic response and the fatigue life of a CVAR with the excitation of regular waves. The current and the regular wave are in the $x$-direction. To balance the calculation's accuracy and computing time, the element divisions of the lower, buoyant, and upper regions are 31,42 , and 178 , respectively, and the length of each element is $10 \mathrm{~m}$. The detailed physical properties of the CVAR are summarized in Table 3.
The static response of the CVAR is shown in Fig. 7. It can be observed that a nearly vertical state occurs at both ends. Thus, the effective tension is relatively larger. In addition, the approximately horizontal segment with a large bending moment in Fig. 7 (a) can be attributed to the buoyancy module.

\subsection{Sensitivity to wave height}

A series of numerical simulations are conducted to investigate the influence of the wave height. Fig. 8 shows the time series of the tensions at the four points (i.e., bottom end, $310 \mathrm{~m}, 730 \mathrm{~m}$, and top end) for the four values of the wave height $\mathrm{H}=6 \mathrm{~m}, 10 \mathrm{~m}$, $14 \mathrm{~m}$, and $18 \mathrm{~m}$ at the wave period of $\mathrm{T}=12 \mathrm{~s}$, current velocity $v=0$, and internal flow density

Table 3. Physical properties of the CVAR for the basic case.

\begin{tabular}{llll}
\hline Properties & Value & Properties & Value \\
\hline Horizontal distance $(\mathrm{m})$ & 585 & Buoyancy factor in lower region & 5 \\
Water depth $(\mathrm{m})$ & 2435 & Gravity factor in the upper region & -1.5 \\
Upper region length $(\mathrm{m})$ & 1780 & Outer diameter of the riser $(\mathrm{m})$ & 0.35 \\
Transition region length $(\mathrm{m})$ & 420 & Axial stiffness $(\mathrm{N})$ & $5.36 \mathrm{e} 9$ \\
Lower region length $(\mathrm{m})$ & 310 & Bending stiffness $\left(\mathrm{N} \cdot \mathrm{m}^{2}\right)$ & $7.12 \mathrm{e} 7$ \\
Buoyancy length in lower region $(\mathrm{m})$ & 190 & Riser material density $\left(\mathrm{kg} / \mathrm{m}^{3}\right)$ & 7850 \\
Gravity length in upper region $(\mathrm{m})$ & 100 & Internal fluid density $\left(\mathrm{kg} / \mathrm{m}^{3}\right)$ & 900 \\
Buoyancy factor in transition region & 1.6 & Internal fluid velocity $(\mathrm{m} / \mathrm{s})$ & 0 \\
\hline
\end{tabular}
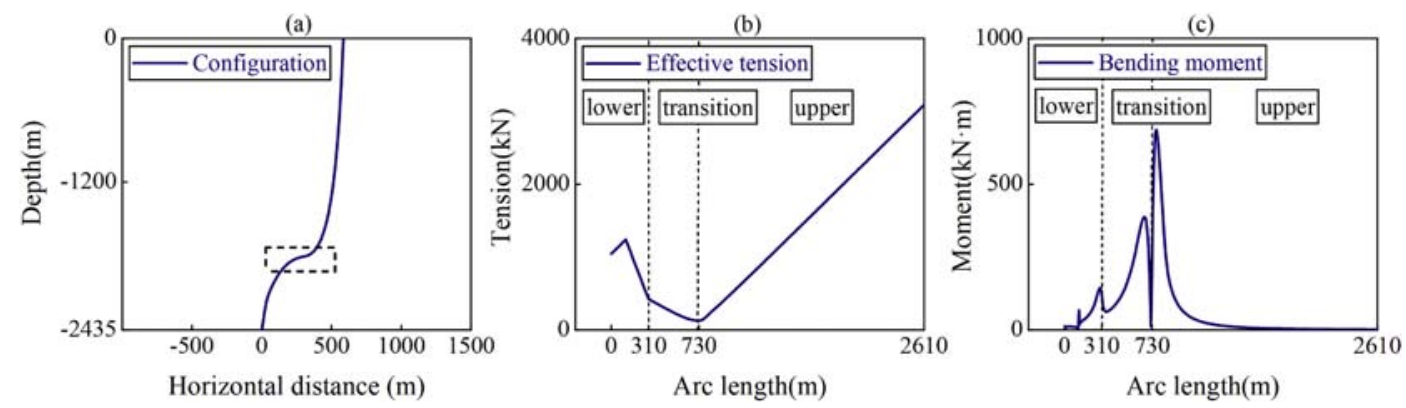

Fig. 7. Static performance of the CVAR. (a) Configuration. (b) Effective tension. (c) Bending moment. 

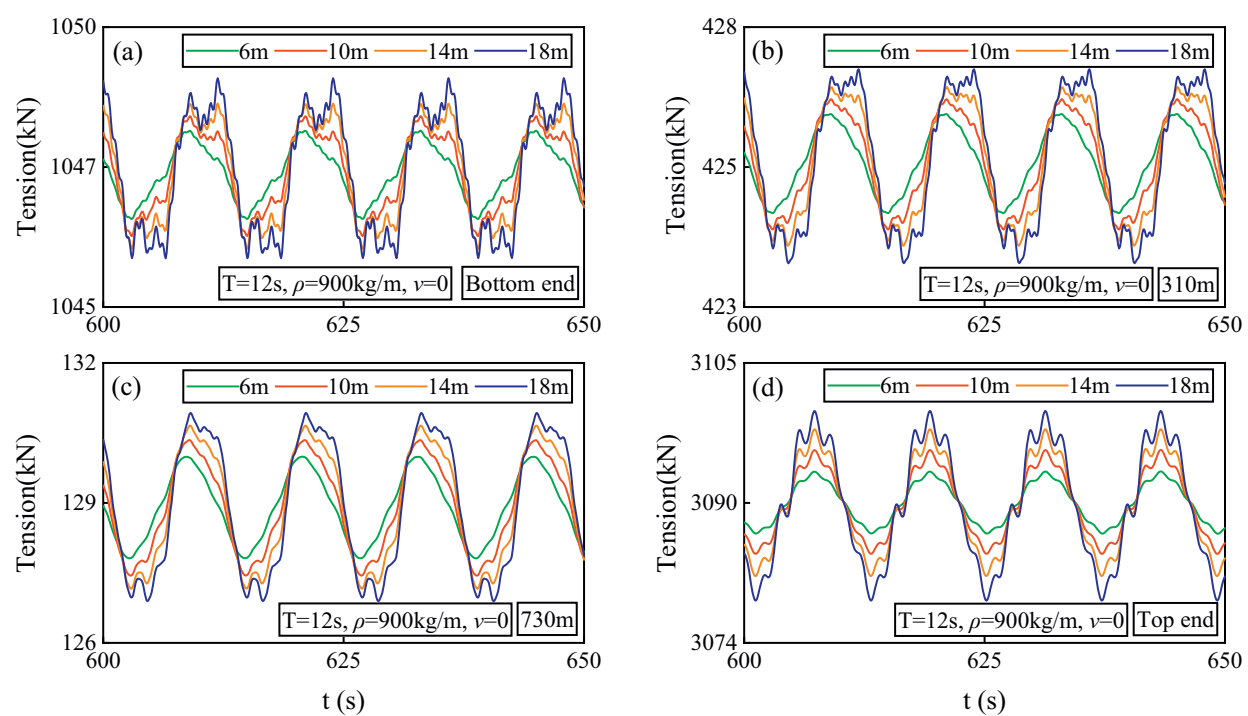

Fig. 8. Time series of tension with different wave heights. (a) Bottom end. (b) $310 \mathrm{~m}$. (c) $730 \mathrm{~m}$. (d) Top end.

Table 4. Tension amplitudes at key points with different wave heights.

\begin{tabular}{lllll}
\hline $\mathrm{H}(\mathrm{m})$ & $T_{a}(\mathrm{kN})$ & $T_{b}(\mathrm{kN})$ & $T_{c}(\mathrm{kN})$ & $T_{d}(\mathrm{kN})$ \\
\hline 6 & 1.45 & 1.70 & 2.03 & 6.88 \\
10 & 1.97 & 2.24 & 2.71 & 11.47 \\
14 & 2.39 & 2.72 & 3.23 & 16.18 \\
18 & 2.96 & 3.33 & 3.77 & 20.88 \\
\hline
\end{tabular}

$\rho=900 \mathrm{~kg} / \mathrm{m}$. With an increase in the incident wave height, the tension amplitudes at the four nodes increase, and the nonlinearity becomes more significant. The tension amplitudes of the specific points in Table 4 show an approximate linear growth trend. However, these amplitudes are much lower than the respective average tension (i.e., less than $6 \%$ for all cases), which indicates that the wave height has a slight influence on the tension. In addition, the amplitudes in the lower parts are relatively small, while those at the top end node are much larger. This difference are more pronounced at higher wave heights because the wave velocity decays exponentially with the increasing depth. It can also be observed that the wave height has a weak effect on the occurrence time of the peak or trough value of the CVAR [6].

Fig. 9 presents the fast Fourier transform (FFT) of the tension time series. It can be observed that the dominant frequency of the CVAR has a constant value of $0.083 \mathrm{~Hz}$, which is consistent with the wave
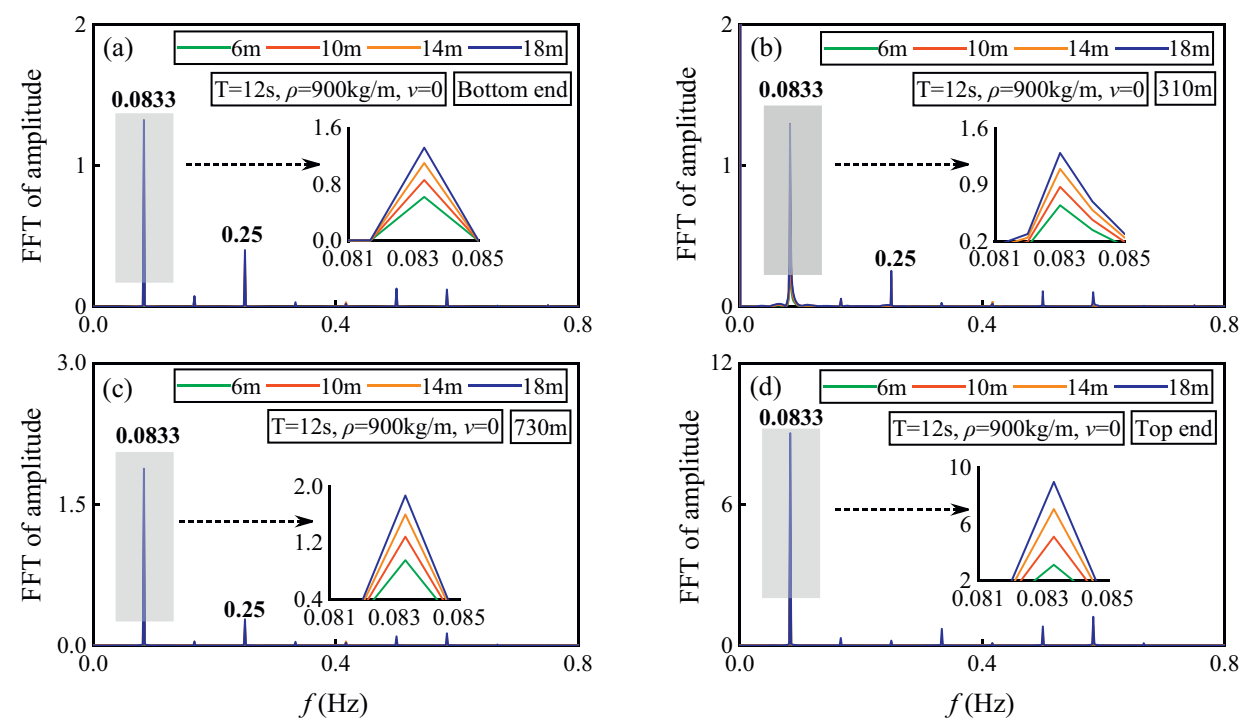

Fig. 9. Fast Fourier transform (FFT) for the time series of tension. (a) Bottom end. (b) $310 \mathrm{~m}$. (c) $730 \mathrm{~m}$. (d) Top end. 

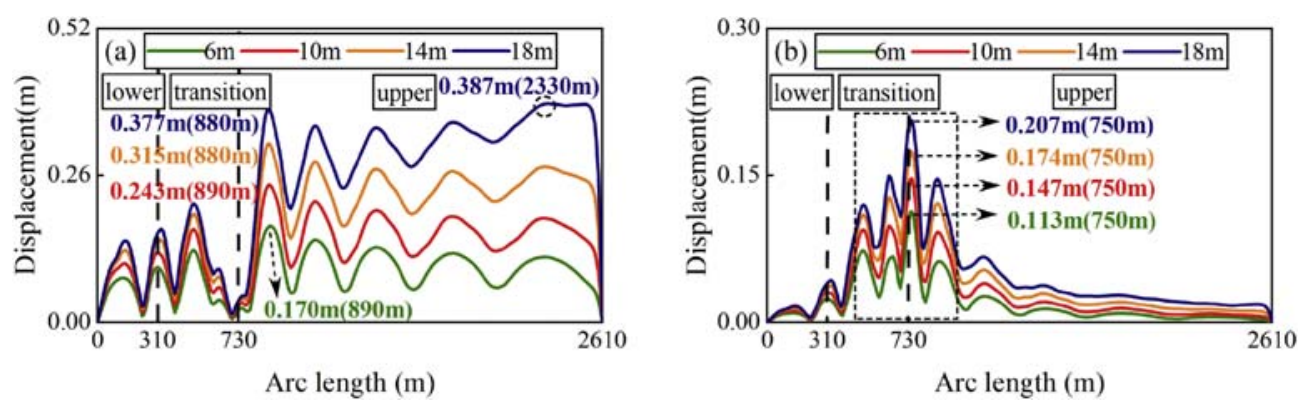

Fig. 10. Displacement envelopes with different wave heights with wave excitation. (a) $x$-direction. (b) z-direction.

excitation frequency. This indicates that the wave height has no significant influence on the dominant frequency. Additionally, a higher frequency $(0.25 \mathrm{~Hz})$ in the lower part of the CVAR can be obtained in Fig. 9 (a) and (b), which indicates the influence of the dynamic response of adjacent riser segments on each other due to the low velocity of the wave particle.

Fig. 10 shows the $x$ - and $z$-direction displacement envelopes for different wave heights. The maximum displacement increases tremendously with the increasing incident wave height, while the positions of the displacement extremums are unchangeable. Therefore, an increase in the wave height can enhance the vibration intensity, but it does not change the dynamic response pattern. As shown in Fig. 10 (a), the displacement in the upper region is larger than that in other regions, and the difference grows with the increase of the wave height. The maximum displacement increases linearly in the increment of $0.072 \mathrm{~m}$, and the corresponding positions of the first three cases are very close (i.e., $890 \mathrm{~m}, 890 \mathrm{~m}$, and $880 \mathrm{~m}$ ). However, the position of the maximum displacement is $280 \mathrm{~m}$ near the top end when the wave height is $18 \mathrm{~m}$, indicating the sensitivity of the top region of the CVAR to the wave height. Fig. 10 (b) reveals that the location corresponding to the maximum displacements is at $750 \mathrm{~m}$. This is because it is close to the horizontal segment of the CVAR. What's more, the low amplitude in most parts is due to the vertical configuration at both ends.

Fig. 11 presents the fatigue life distribution along the CVAR. The horizontal axis is the location of the riser (from the bottom to the top), and the vertical axis is the fatigue life presented in logarithmic form. The fatigue life decreases dramatically with the increasing wave height, and there are three points (i.e., No.1, No.2, and No.3) where the fatigue life variation is apparent. The fatigue lives at the wave heights of $6 \mathrm{~m}, 10 \mathrm{~m} 14 \mathrm{~m}$, and $18 \mathrm{~m}$ are 100 years, 56 years, 54 years, and 37 years at No.1; 2365 years, 900 years, 514 years, and 368 years at No.2; and 39,291 years, 771 years, 111 years, and 25 years at No.3. Because No.1 and No.2 are at the junction between the bare riser and the buoyancy segment, the large stress ranges of the bending moment primarily lead to severe fatigue damage. The fatigue life at the top end is lower because the axial stress range is relatively large.

\subsection{Sensitivity to wave period}

With the internal flow density and the current velocity kept constant, Figs. 12 and 13 illustrate the time series and the FFT of the tension, respectively, at the four points (i.e., bottom end, $310 \mathrm{~m}, 730 \mathrm{~m}$, and top end) for the four cases of the wave periods $\mathrm{T}=8 \mathrm{~s}, 12 \mathrm{~s}, 16 \mathrm{~s}$, and $20 \mathrm{~s}$ at the wave height of $\mathrm{H}=10 \mathrm{~m}$. As shown in Fig. 12 and Table 5, the tension amplitudes grow with the increase of the wave period, and their nonlinearity gradually decreases. Fig. 13 shows that the excitation frequency dominates the dynamic responses of the CVAR. The higher-order frequencies of $0.25 \mathrm{~Hz}$ and $0.375 \mathrm{~Hz}$ can also be observed in the first two subplots.

Fig. 14 shows the displacement envelopes in both the $\mathrm{x}$ and $\mathrm{z}$ directions for different wave periods. It can be found that the larger wave period results in a

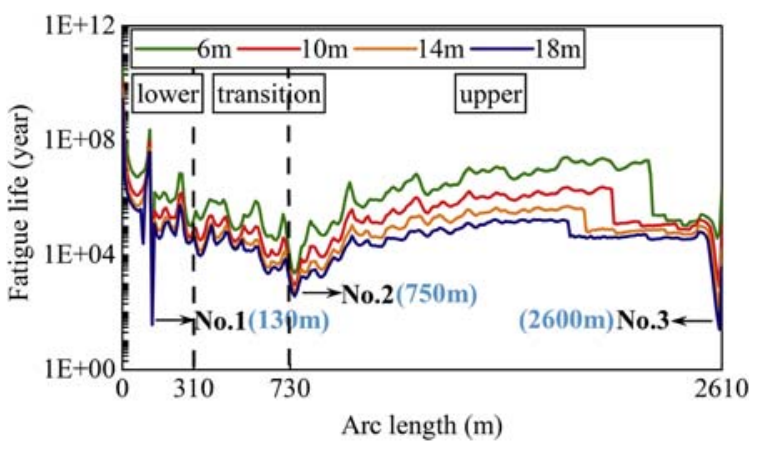

Fig. 11. Comparison of the fatigue life distributions with wave heights. 

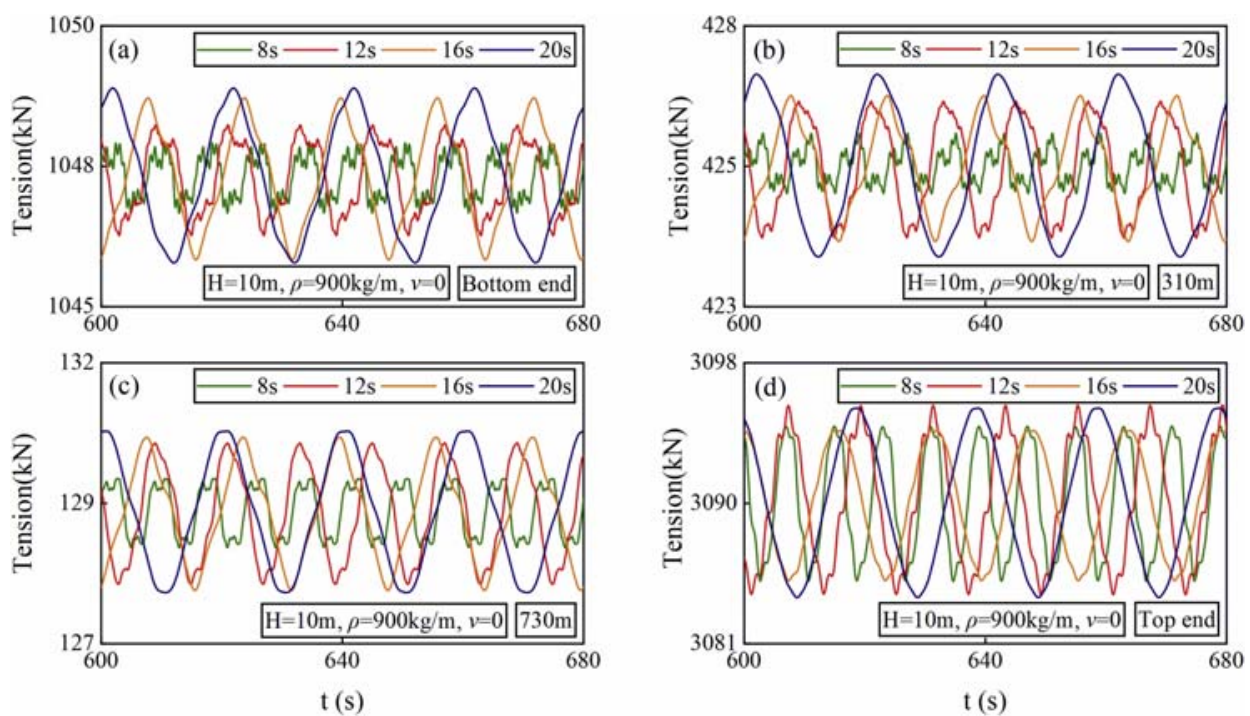

Fig. 12. Time series of tension with different wave periods. (a) Bottom end. (b) $310 \mathrm{~m}$. (c) $730 \mathrm{~m}$. (d) Top end.
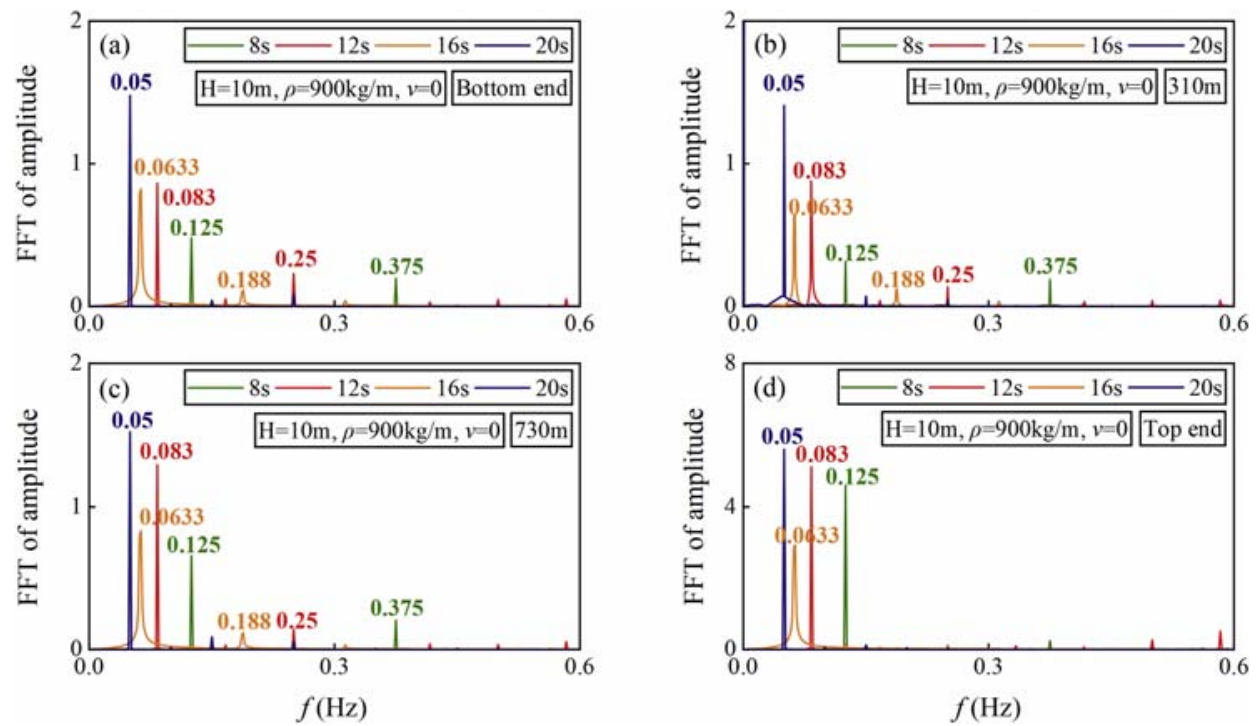

Fig. 13. FFT for the time series of tension. (a) Bottom end. (b) $310 \mathrm{~m}$. (c) $730 \mathrm{~m}$. (d) Top end.

larger maximum displacement amplitude. In Fig. 14 (a), the displacement curve in the upper region fluctuates heavily, and the maximum displacements for the four wave periods of $8 \mathrm{~s}, 12 \mathrm{~s}, 16 \mathrm{~s}$, and $20 \mathrm{~s}$ also occur in this region, which are $0.103 \mathrm{~m}, 0.243 \mathrm{~m}$, $0.352 \mathrm{~m}$, and $0.479 \mathrm{~m}$ with the specific positions of

Table 5. Tension amplitudes at key points with different wave periods.

\begin{tabular}{lllll}
\hline $\mathrm{T}(\mathrm{s})$ & $T_{a}(\mathrm{kN})$ & $T_{b}(\mathrm{kN})$ & $T_{c}(\mathrm{kN})$ & $T_{d}(\mathrm{kN})$ \\
\hline 8 & 1.25 & 0.99 & 1.33 & 9.38 \\
12 & 1.97 & 2.24 & 2.71 & 11.47 \\
16 & 2.88 & 2.39 & 2.94 & 9.09 \\
20 & 3.11 & 2.99 & 3.10 & 11.46 \\
\hline
\end{tabular}

$900 \mathrm{~m}, 890 \mathrm{~m}, 930 \mathrm{~m}$ and $990 \mathrm{~m}$, respectively. The displacement increments are in the range of 0.11-0.14 $\mathrm{m}$, and the corresponding positions move up along the riser. As shown in Fig. 14 (b), the displacement in the transition region is found to increase remarkably, while those of the other regions are insensitive to the wave period. The variation of the location corresponding to the maximum displacement is relatively small (i.e., $610 \mathrm{~m}, 750 \mathrm{~m}$, $740 \mathrm{~m}$, and $730 \mathrm{~m}$ ) when the period exceeds $12 \mathrm{~s}$. From Figs. 12-14, it can be concluded that the excitation of regular waves with a high frequency can result in the decrease of the riser's dynamic amplitude. However, it will lead to a high-frequency 

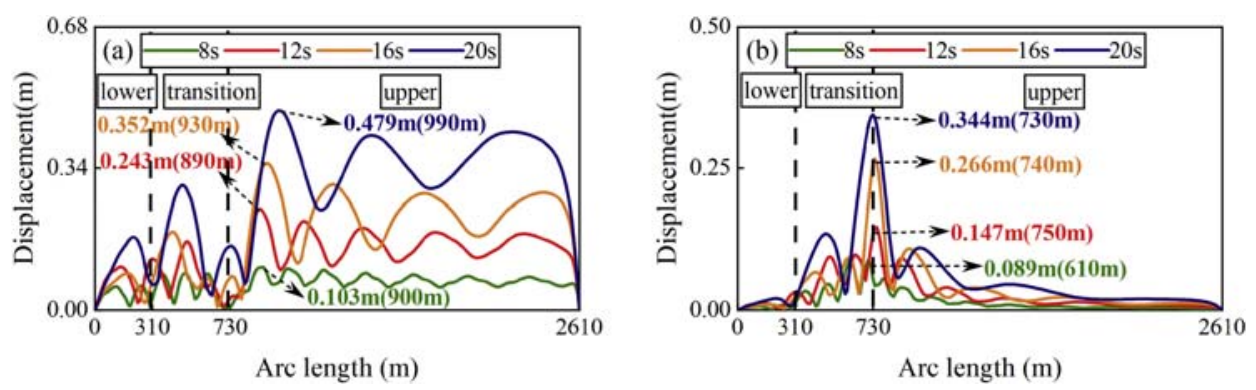

Fig. 14. Displacement envelopes with different wave periods with wave excitation. (a) $x$-direction. (b) z-direction.

oscillation of the CVAR, possibly triggering the fatigue crack extension.

Fig. 15 depicts the fatigue life distribution along the CVAR. Although the stress range is elevated, the fatigue life of the riser increases as the total fatigue damage accumulation decreases with the increasing wave period. The fluctuations of the fatigue life curves are also reduced appreciably due to the decrease in the nonlinearity. The minimum fatigue lives in the top region are 306 years, 771 years, 2461 years, and 11,101 years at the wave periods of $8 \mathrm{~s}$, $12 \mathrm{~s}, 16 \mathrm{~s}$, and 20s, respectively. This indicates that the fatigue damage at the top end is sensitive to the wave period. The fatigue life of the buoyancy section is found to vary slightly due to the limitation of the drag force on the extended stress ranges.

\subsection{Sensitivity to internal flow density}

The internal flow density is another key factor that influences the dynamic behavior of risers [24]. A sensitivity analysis is conducted to investigate the effects of the internal flow density on the CVAR, as described in this subsection. Keeping the wave parameters and current velocity constant (i.e., $\mathrm{H}=10 \mathrm{~m}, \mathrm{~T}=12 \mathrm{~s}$ and $v=0$ ), Figs. 16 and 17 show the time series and the FFT of the tension at the bottom end, $130 \mathrm{~m}, 730 \mathrm{~m}$, and top end for different

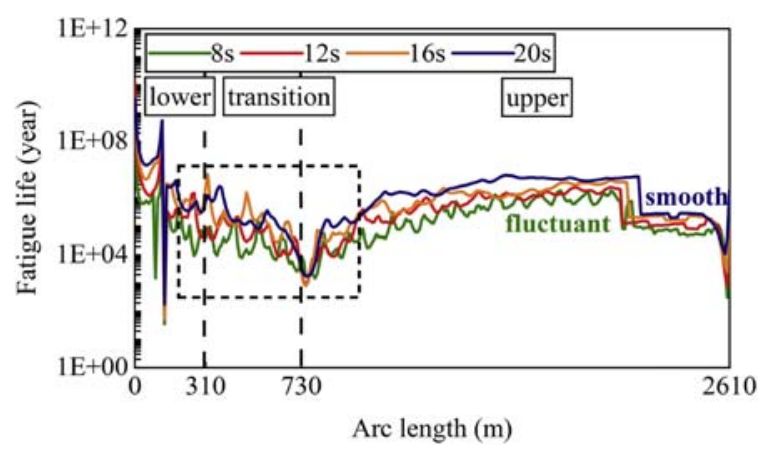

Fig. 15. Comparison of fatigue life distributions with wave periods. internal flow densities (i.e., $700 \mathrm{~kg} / \mathrm{m}, 800 \mathrm{~kg} / \mathrm{m}$, $900 \mathrm{~kg} / \mathrm{m}$, and $1000 \mathrm{~kg} / \mathrm{m}$ ) are obtained. The tension amplitudes of the specific points are listed in Table 6. As shown in Fig. 16 (a) and (b), a significant downward trend in the average tension is obtained when considering the inflow density. This is because the increase in the inflow density compromises part of the tension provided by the buoyancy module. However, this follows an opposite trend in Fig. 16 (c) and (d), which may be due to the increase in the inflow density being equivalent to an increase in the riser's submerged weight at these two points. Table 6 shows that the tension amplitudes of key points (i.e., bottom end, $130 \mathrm{~m}, 730 \mathrm{~m}$, and top end) increase by $39.3 \%, 29.4 \%, 9.1 \%$, and $41.8 \%$, respectively, as the internal flow density increases from $700 \mathrm{~kg} / \mathrm{m}$ to $1000 \mathrm{~kg} / \mathrm{m}$. It can be found that the tension amplitude at $730 \mathrm{~m}$ varies slightly. Additionally, the maximum amplitude variation is less than $0.59 \mathrm{kN}$ among the first three positions, while that at the top end is relatively large (i.e., $4.41 \mathrm{kN}$ ), indicating that the top tension amplitude is sensitive to the internal flow density. It can be seen from Fig. 17 that the internal flow has an extremely weak influence on the dominant frequency.

The displacement envelopes with four internal flow densities in both the $\mathrm{x}$ and $\mathrm{z}$ directions are shown in Fig. 18. It can be observed that the displacements among the four cases follow a nearly same curve shape. The maximum displacements in the $\mathrm{x}$-direction are all $0.242 \mathrm{~m}$ at the same position of $890 \mathrm{~m}$ for the four cases, as shown in Fig. 18 (a). However, there is a slight decreasing trend in a few parts of the upper region for the displacement. This is because the inertia force rises in concert with the inflow density. Fig. 18 (b) shows that the maximum displacement grows gradually with an average increment of $0.08 \mathrm{~m}$, moving the location slightly down to the bottom end.

The fatigue life distributions along the CVAR due to the internal fluid density changes are illustrated in Fig. 19. It can be seen that the internal 

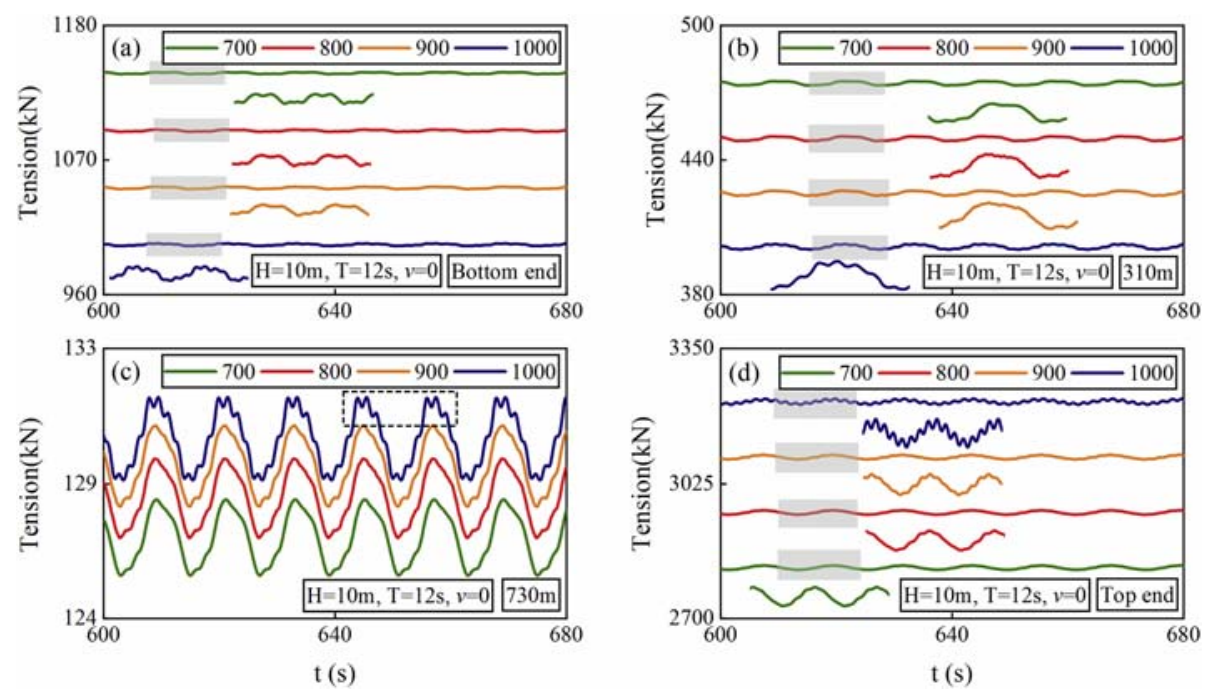

Fig. 16. Time series of tension with different internal flow densities with wave excitation. (a) Bottom end. (b) $310 \mathrm{~m}$. (c) $730 \mathrm{~m}$. (d) Top end.
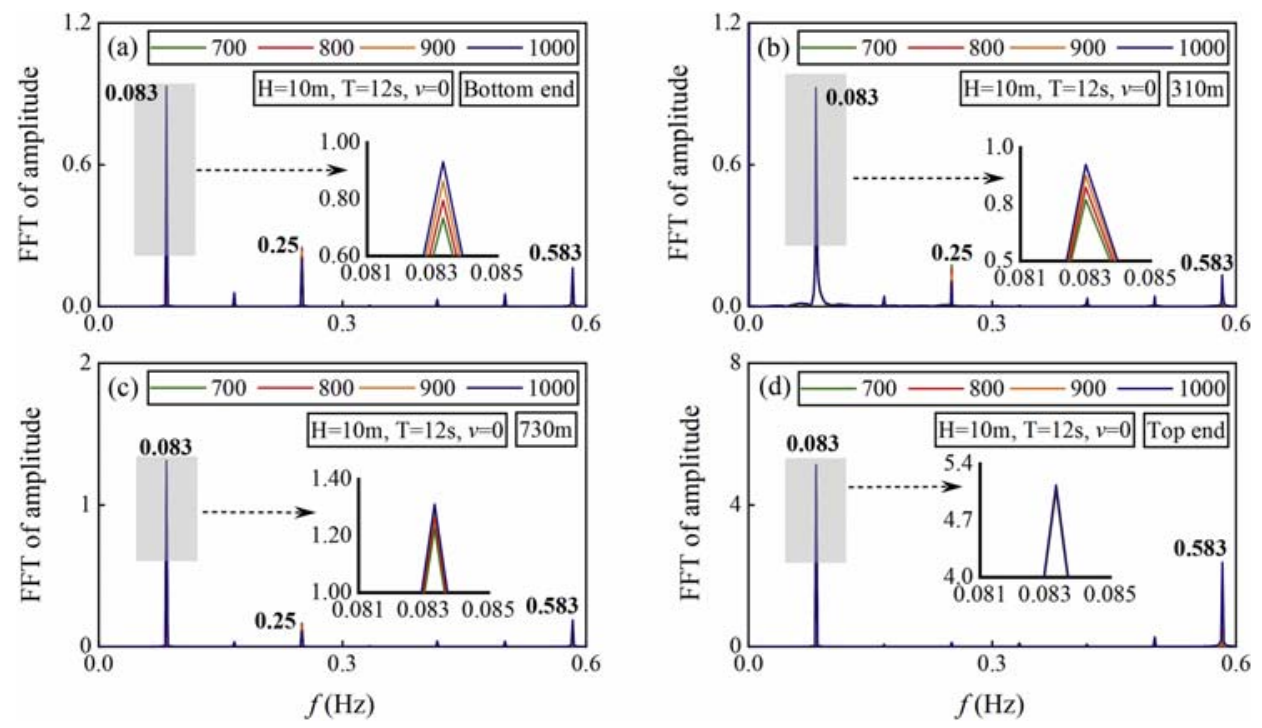

Fig. 17. FFT for the time series of tension. (a) Bottom end. (b) $310 \mathrm{~m}$. (c) $730 \mathrm{~m}$. (d) Top end.

flow density has a weak influence on the fatigue life in most regions of the CVAR. The position of the minimum fatigue life in the lower region moves down to the bottom end when the internal flow density increases from 900 to $1000 \mathrm{~kg} / \mathrm{m}$. This is because the position of the bending point in the

Table 6. Tension amplitude at key points with different internal flow densities.

\begin{tabular}{lllll}
\hline$\rho(\mathrm{kg} / \mathrm{m})$ & $T_{a}(\mathrm{kN})$ & $T_{b}(\mathrm{kN})$ & $T_{c}(\mathrm{kN})$ & $T_{d}(\mathrm{kN})$ \\
\hline 700 & 1.50 & 1.87 & 2.54 & 10.55 \\
800 & 1.80 & 2.08 & 2.65 & 10.82 \\
900 & 1.97 & 2.24 & 2.71 & 11.47 \\
1000 & 2.09 & 2.42 & 2.77 & 14.96 \\
\hline
\end{tabular}

bare riser of the lower region descends with a higher internal flow density. Fig. 19 also shows that there is an obvious difference in the fatigue life near the top-end node. However, the resultant fatigue life value has a high order of magnitude due to the small fatigue damage. Thus, the difference is negligible for practical applications.

\subsection{Sensitivity to current velocity}

When the CVAR is subjected to wave-current loads, the results may be very different because of the relative velocity variations between the structure and the fluid. Hence, the effect of the external current velocities on the CVAR is investigated 

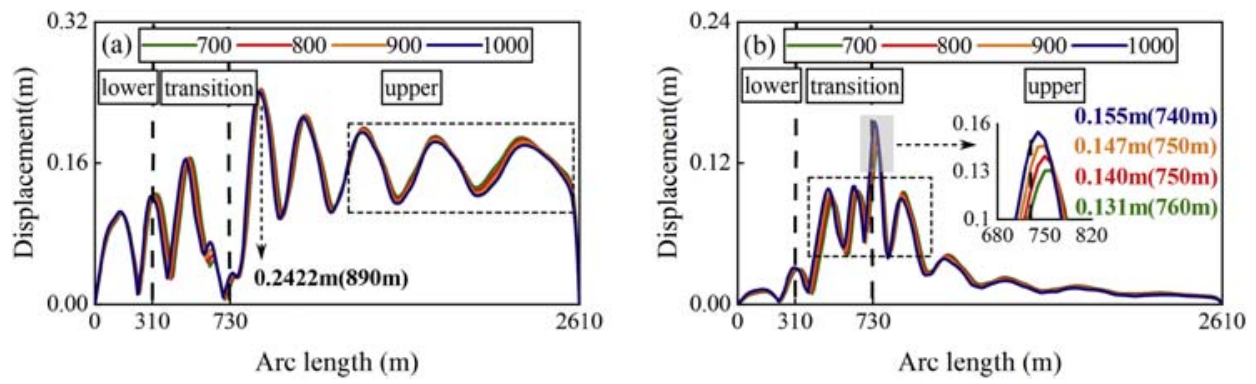

Fig. 18. Displacement envelopes with different internal flow densities with wave excitation. (a) $x$-direction. (b) $z$-direction.

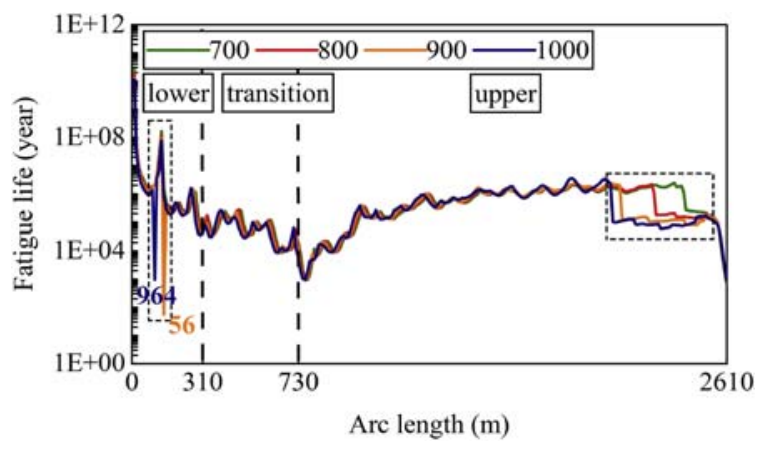

Fig. 19. Comparison of fatigue life distributions with internal flow density.

comprehensively, keeping the constant wave parameters and internal flow density (i.e., $\mathrm{H}=10 \mathrm{~m}$, $\mathrm{T}=12 \mathrm{~s}$, and $\rho=900 \mathrm{~kg} / \mathrm{m}$ ). The comparison of the tension, in terms of the time series and the spectrum, is shown in Figs. 20 and 21, respectively. The tension amplitudes of the specific points are listed in Table 7. An increase in the current velocity increases the average tension, as shown in Fig. 20, but it has little effect on the occurrence of the maximum tension. The tension amplitude decreases sharply at the bottom end, $310 \mathrm{~m}$, and $730 \mathrm{~m}$ by $95.5 \%, 96 \%$, and $96.5 \%$ in Table 7 , indicating that the current velocity has a significant effect on the dynamic responses of the CVAR. However, a decrease of only $16 \%$ occurs at the top end. This is attributed to the top region being less deformed. It can be seen from Fig. 21 that the current velocity has little influence on the dominant frequency. As expected, the higher-order frequencies always exist in the lower parts of the CVAR, regardless of the changes in the various parameters, confirming that the high-order frequency can be associated with the riser structure.

Fig. 22 presents the displacement envelopes with different current velocities in both the $x$ and $z$ directions. As shown in Fig. 22 (a), the maximum displacement drops by approximately $0.043 \mathrm{~m}$ in the velocity range of $0-0.2 \mathrm{~m} / \mathrm{s}$, but it grows by $0.016 \mathrm{~m}$ at $0.3 \mathrm{~m} / \mathrm{s}$. The locations corresponding to the maximum displacements move up from the
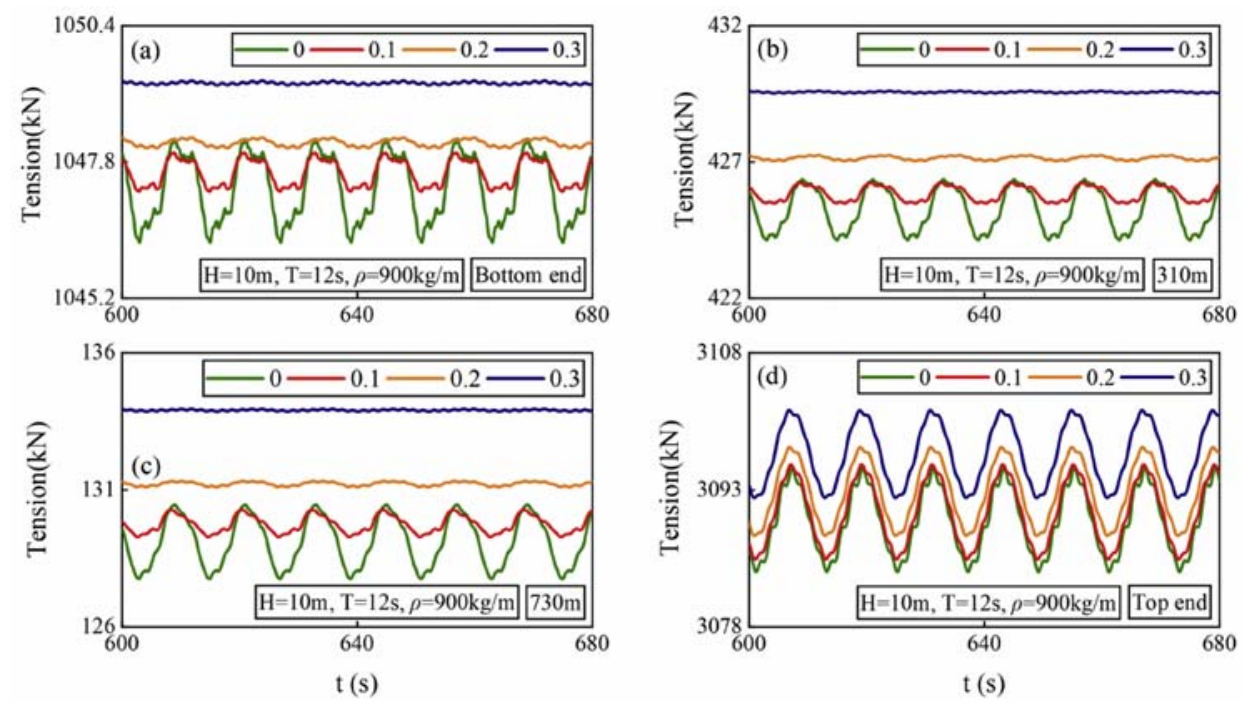

Fig. 20. Time series of tension with different flow velocities with wave excitation. (a) Bottom end. (b) $130 \mathrm{~m}$. (c) $730 \mathrm{~m}$. (d) Top end. 

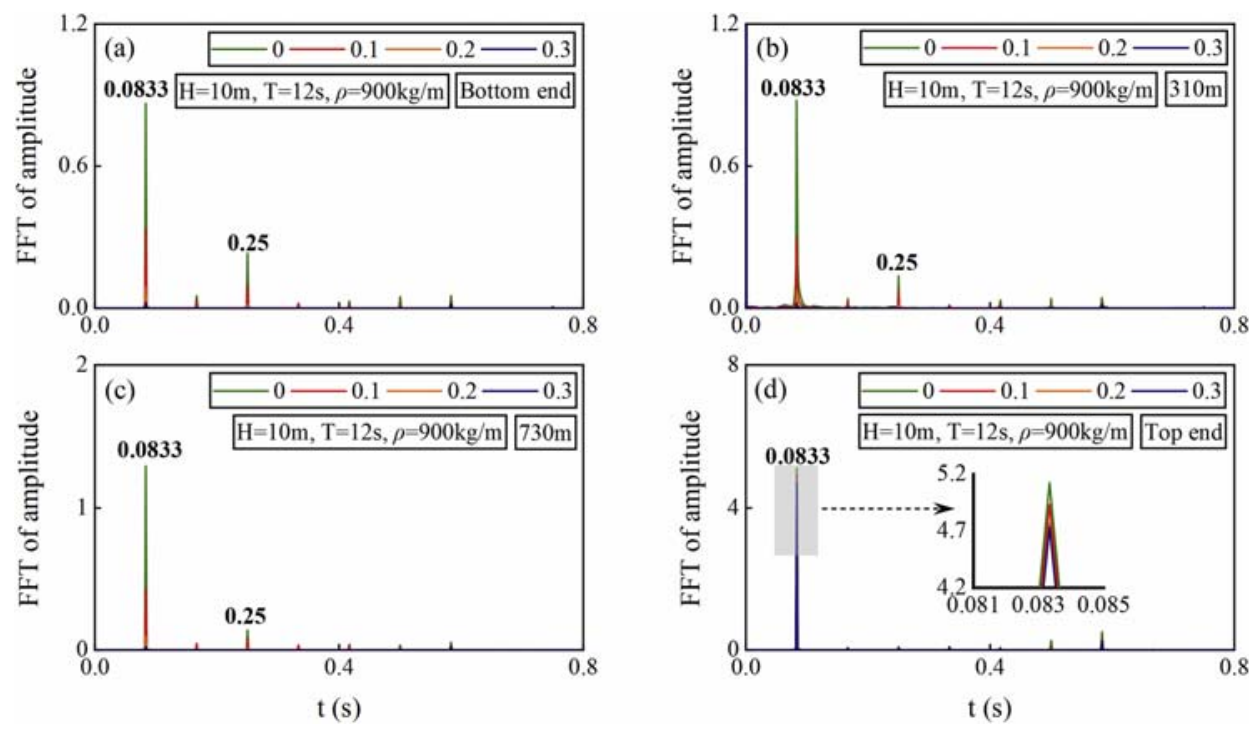

Fig. 21. FFT for the time series of tension. (a) Bottom end. (b) $130 \mathrm{~m}$. (c) $730 \mathrm{~m}$. (d) Top end.

Table 7. Tension amplitude at key points with different current velocities.

\begin{tabular}{lllll}
\hline$v(\mathrm{~m} / \mathrm{s})$ & $T_{a}(\mathrm{kN})$ & $T_{b}(\mathrm{kN})$ & $T_{c}(\mathrm{kN})$ & $T_{d}(\mathrm{kN})$ \\
\hline 0 & 1.97 & 2.24 & 2.71 & 11.47 \\
0.1 & 0.73 & 0.75 & 0.99 & 10.48 \\
0.2 & 0.20 & 0.21 & 0.22 & 9.74 \\
0.3 & 0.088 & 0.089 & 0.095 & 9.63 \\
\hline
\end{tabular}

bottom end to the top end (i.e., $890 \mathrm{~m}, 1820 \mathrm{~m}$, $2500 \mathrm{~m}$, and $2510 \mathrm{~m}$ ), also indicating that the variation in the position is smaller at high current velocities. Fig. 22 (b) shows that an increase in the current velocity diminishes the displacement sharply, moving the locations of the maximum displacements down to the bottom along the CVAR gradually. However, the displacement is close to 0 at a velocity of $0.3 \mathrm{~m} / \mathrm{s}$, indicating that high current velocity has a suppression effect on the dynamic response of the riser.

Fig. 23 shows the wave-induced fatigue life with the inclusion of the external currents. The plot demonstrates that the fatigue life in most parts of

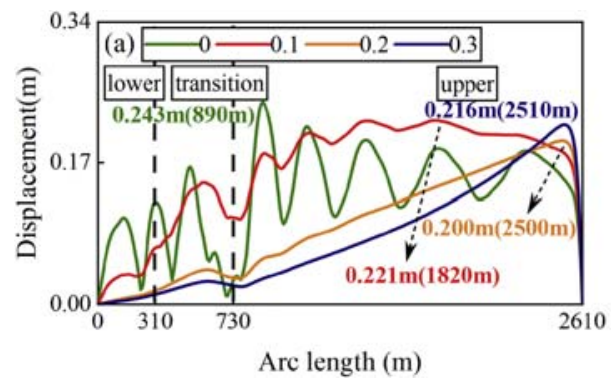

the riser grows significantly with the increasing current velocity due to the increased drag force having a limiting effect on the vibration. However, the fatigue life near the top area remains almost constant. Although the current has a positive influence on the fatigue life, higher current velocities may result in the loss of the vertical state at both ends of the riser [13].

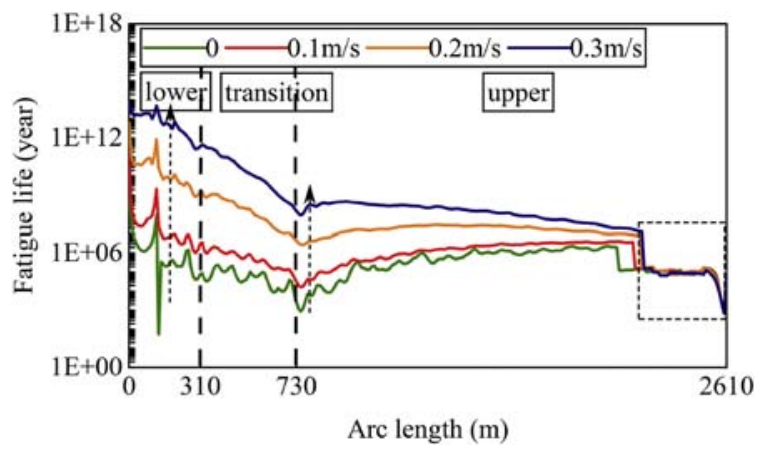

Fig. 23. Comparison of fatigue life distributions with current velocity.

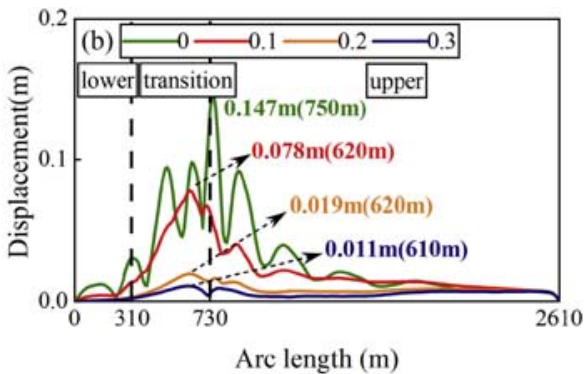

Fig. 22. Displacement envelops with different flow velocities with wave excitation. (a) $x$-direction. (b) $z$-direction. 


\section{Conclusion}

A CVAR is a novel type of slender riser with a huge cost superiority that allows interventions to be implemented on a well bore from a platform. In this paper, the effects of the wave height and period, internal flow density, and current velocity on the dynamic response and the fatigue life of the CVAR excited by regular waves are studied. The key conclusions are drawn based on the extensive numerical analysis as follows.

(1) The wave height plays a considerable role in the dynamic response and its nonlinearity. The upper region of the CVAR is more sensitive to the wave height than the lower region, and this phenomenon is more pronounced at higher wave heights.

(2) A high frequency of the wave excitation reduces the tension and displacement amplitudes of the CVAR. The fatigue life increases moderately due to the decrease in the total fatigue damage accumulation.

(3) An increase in the internal flow density slightly changes the displacement and tension amplitudes of the CVAR, but the average tension varies significantly. The fatigue life of the lower region are sensitive to the internal flow density.

(4) The external current suppresses the dynamic response of most regions for the CVAR, and the fatigue life along the riser improves remarkably. However, the riser can lose the advantage of the vertical access to the well bore at higher current velocity.

The above analyses indicate the strong dependence of the dynamic response and the fatigue life of the CVAR on these parameters. The achievements of this study facilitate the provision of technical support for the practical applications of a CVAR. Furthermore, the effects of nonlinear waves and nonuniform currents on the dynamic performance of a CVAR can be studied in the future.

\section{Acknowledgments}

This work was supported by the National Natural Science Foundation of China (U2006226; 51979257), the Key Technology Research and Development Program of Shandong, China (2018GHY115045), and the Shandong Provincial Natural Science Foundation, China (ZR2020ME261; ZR2019MEE032).

\section{References}

[1] Anzai H, Endo T. On-site indication of fatigue damage under complex loading. Int J Fatig 1979;1(1):49-57.
[2] API RP 2A WSD. Recommended practice for planning, designing and constructing fixed offshore platforms -working stress design. 2010.

[3] Bai XL, Vaz MA, Morooka CK, Xie YH. Dynamic tests in a steel catenary riser reduced scale model. Ships Offshore Struct 2017;12(8):1064-76.

[4] Brinkmann CR, Whooley KT. Design study of a deepwater compliant vertical access riser for the Gulf of Mexico. In: Proceedings of the ASME 21st international conference, offshore mechanics and arctic engineering; 2002.

[5] Chen XH. Studies on dynamic interaction between deep-water floating structures and their mooring/tendon system. PhD Thesis. College Station, Texas: Texas A\&M University; 2002.

[6] Cheng Y, Tang LY, Fan TH. Dynamic analysis of deepwater steel lazy wave riser with internal flow and seabed interaction using a nonlinear finite element method. Ocean Eng 2020;209:107498.

[7] Dong XY, Shiri H. Performance of non-linear seabed interaction models for steel catenary risers, part II: global response. Appl Ocean Res 2019;82:158-74.

[8] Garrett DL. Dynamic analysis of slender rods. J Energy Resour Technol 1982;104:302-6.

[9] Lenci S, Callegari M. Simple analytical models for the J-lay problem. Acta Mech 2005;178:23-39.

[10] Liu M, Cross C. Fatigue design and analysis of offshore pipelines and risers subjected to waves and currents. J Offshore Mech Arctic Eng 2018;140(2):021701.

[11] Liu Z, Guo HY. Sensitivity analysis of steep wave riser with internal flow. J Mar Sci Technol 2018;26(4):541-51.

[12] Lou M, Li R, Wu WG, Chen ZS. Static performance analysis of deepwater compliant vertical access risers. Int J Naval Arch Ocean Eng 2019;11(2):970-9.

[13] Lou M, Liang WX, Li R. Experimental and numerical study of dynamic performance of CVAR subjected to regular wave and platform motion. Ocean Eng 2020;199:106946.

[14] Martins MAL, Silveira ESS. Statistical design of experiments applied to the design of compliant vertical access risers. In: ASME 31st international conference on ocean, offshore arctic engineering; 2012.

[15] Martins MAL, Lages EN, Silveira SS. Compliant vertical access riser assessment: DOE analysis and dynamic response optimization. Appl Ocean Res 2013;4:28-40.

[16] Mungall C, Haverty K, Bhat S, Andersen D, Sarkar I, Wu J. Semisubmersible based dry tree platform with compliant vertical access risers. In: Offshore Technology conference; 2004.

[17] Paidoussis M. Fluid-structure interactions: slender structures and axial flow. Academic Press; 1998.

[18] Paulling JR, Webster WC. A consistent large amplitude analysis of the coupled response of a TLP and Tendon System. In: Proceedings of the 5th OMAE Symposium, Japan; 1986. p. 126-33.

[19] Pearce JL, Sizer PS, Gano JC, Yonker JH, Thurman RL, OSullivan JF, et al. Method and system for maintenance and servicing of subsea wells, United States Patent No. 4730677. 1988.

[20] Recommended practice DNV-RP-C203. 2008.

[21] Recommended practice DNV-RP-C203. 2010.

[22] Romero I. A comparison of finite elements for nonlinear beams: the absolute nodal coordinate and geometrically exact formulations. Multibody Syst Dyn 2008;20(1):51-68.

[23] Ruan WD, Bai Y, Cheng P. Static analysis of deepwater lazywave umbilical on elastic seabed. Ocean Eng 2014;91:73-83.

[24] Vásquez MJA, Avila JPJ. A parametric analysis of the influence of the internal slug flow on the dynamic response of flexible marine risers. Ocean Eng 2019;174:169-85.

[25] Wang JG, Fu SX, Baarholm R, Zhang MM, Liu C. Global motion reconstruction of a steel catenary riser under vessel motion. Ships Offshore Struct 2019;14(5):442-56.

[26] Yang M, Teng B, Ning D, Shi Z. Coupled dynamic analysis for wave interaction with a truss spar and its mooring line/riser system in time domain. Ocean Eng 2012;39: 72-87. 